\title{
Full Mouth Rehabilitation with Implant-Supported Prostheses for Severe Periodontitis: A Case Report
}

\author{
Sompop Bencharit ${ }^{1, *}$, Debra Schardt-Sacco ${ }^{2}$, Michael B. Border ${ }^{3}$ and Colin P. Barbaro ${ }^{4}$ \\ ${ }^{I}$ Department of Prosthodontics, School of Dentistry; and Department of Pharmacology, School of Medicine, University \\ of North Carolina, Chapel Hill, NC, USA \\ ${ }^{2}$ Department of Oral and Maxillofacial Surgery, School of Dentistry, University of North Carolina, Chapel Hill, NC, \\ USA; and Private Practice, Chapel Hill, NC, USA \\ ${ }^{3}$ Department of Prosthodontics, School of Dentistry, University of North Carolina. Chapel Hill, NC, USA; and Univer- \\ sity of Mount Union, Alliance, $\mathrm{OH}$, USA \\ ${ }^{4}$ Department of Prosthodontics, School of Dentistry, University of North Carolina, Chapel Hill, NC, USA
}

\begin{abstract}
Oral rehabilitation for a patient with severe loss of alveolar bone and soft tissue resulting from severe periodontitis presents a challenge to clinicians. Replacing loosening natural teeth with fixed prostheses supported by dental implants often requires either gingival surgery or bone grafting. The outcome of the bone grafting is sometimes unpredictable and requires longer healing time and/ or multiple surgeries. The presence of periodontal inflammation and periapical lesions often delay the placement of bone grafts as well as dental implants. Here we present a clinical case of a patient undergone full mouth reconstruction with implant-supported fixed prostheses. We demonstrated that early placement of implants (three weeks after extractions) with minimal bone grafting may be an alternative to conventional bone grafting followed by implant placement. We believe that primary stability during implant placement may contribute to our success. In addition, composite resin gingival material may be indicated in cases of large fixed implant prostheses as an alternative to pink porcelain.
\end{abstract}

Keywords: Dental implants, Full mouth rehabiliation, Full mouth reconstruction, Periodontitis, Early implant placement.

\section{INTRODUCTION}

Chronic advanced periodontitis can result in severe loss of periodontium, which is often associated with systemic conditions. Among these conditions, heavy smoking is linked to the degree of severity of periodontal disease $[1,2]$. Restoring the oral function and esthetics in these patients becomes a challenge and requires major bone grafting or artificial gingival tissue. Bone grafting is usually required before placing dental implants [3,4]. However, horizontal bone augmentation procedures are often difficult and offer an unpredictable result [5]. Furthermore, in patients with chronic periodontitis with multiple endo-periodontal lesions, the remaining infection often prevents simultaneous tooth extractions and bone grafting or immediate placement of implants [6].

Here we present a case report of a patient, suffering from severe alveolar bone loss, who had undergone a full mouth reconstruction with dental implants. We also presented an option of extractions with minimal bone grafting and early placement of implants after tooth extractions. We had restored the oral function and esthetics of these patients with fixed screw-retained implant supported prostheses.

*Address correspondence to this author at the CB \#7450, Department of Prosthodontics, School of Dentistry, University of North Carolina, Chapel Hill, NC 27599-7450, USA; Tel: 919-843-8734; Fax: 919-966-3821; E-mail: Sompop_Bencharit@dentistry.unc.edu

\section{CLINICAL REPORT}

\section{Preoperative Information and Treatment Planning}

A 49-year-old Asian male presented to the University of North Carolina Dental Faculty Practice with the chief complaint of "All my teeth are loosening and I need fixed bridges." The Patient reported that he was in good health and had no known allergy. However, he smoked about one to two packs of cigarettes a day for over thirty years. Clinically, almost all of his remaining teeth appeared to have second to third degree mobility (Fig. 1a,b,c,d preoperative photographs). Most of his maxillary anterior teeth appeared to have less than 10 percent remaining alveolar bone support. These teeth were loosening and appeared to suffer from traumatic occlusion secondary from the condition of advanced loss of periodontal support and flare out of their original positions. Most of his molars also had significant bone loss and through-and-through furcation involvement. Many teeth also exhibited communication between periodontal lesions and apical lesions (Fig. 2a,b -preoperative CTscans). Based on the Prosthodontic Diagnostic Index (PDI), the American College of Prosthodontists' Classification System for the Dentate Patients, this patient was a PDI class IV. A treatment plan was constructed including removal of all his remaining teeth, immediate complete dentures, implant placement, and fixed implant-supported prostheses. 
Figure 1a

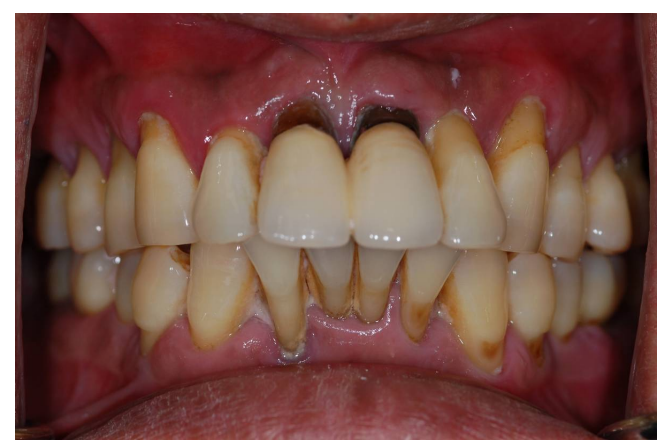

Figure 1c

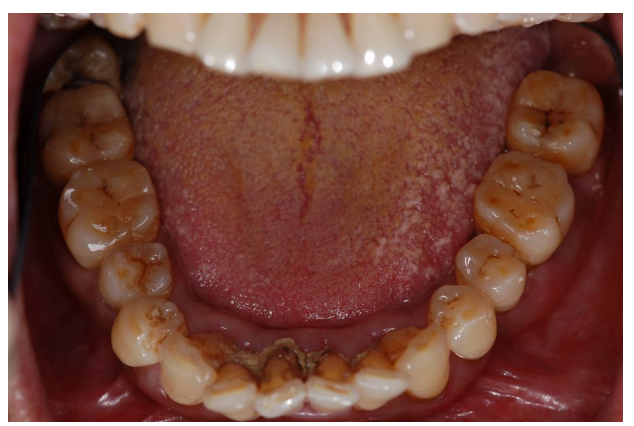

Figure 1b

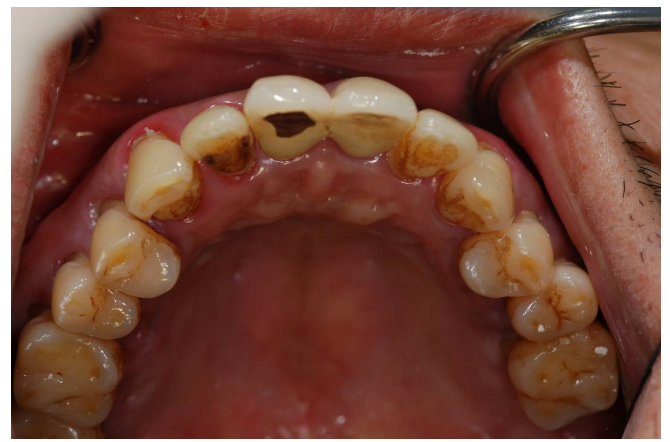

Figure 1d

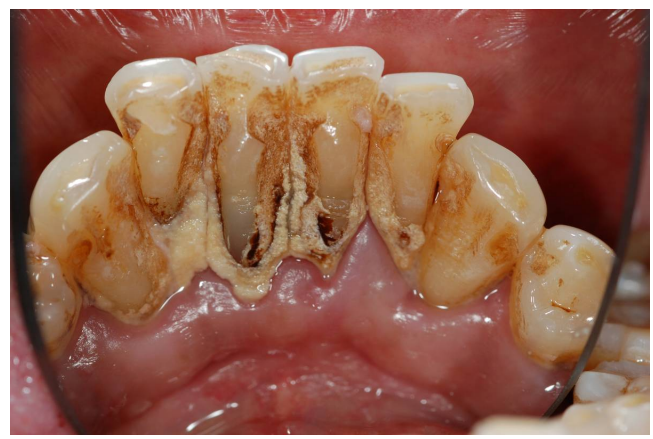

Fig. (1). a-d) Preoperative intraoral photographs.

Figure $2 \mathrm{a}$

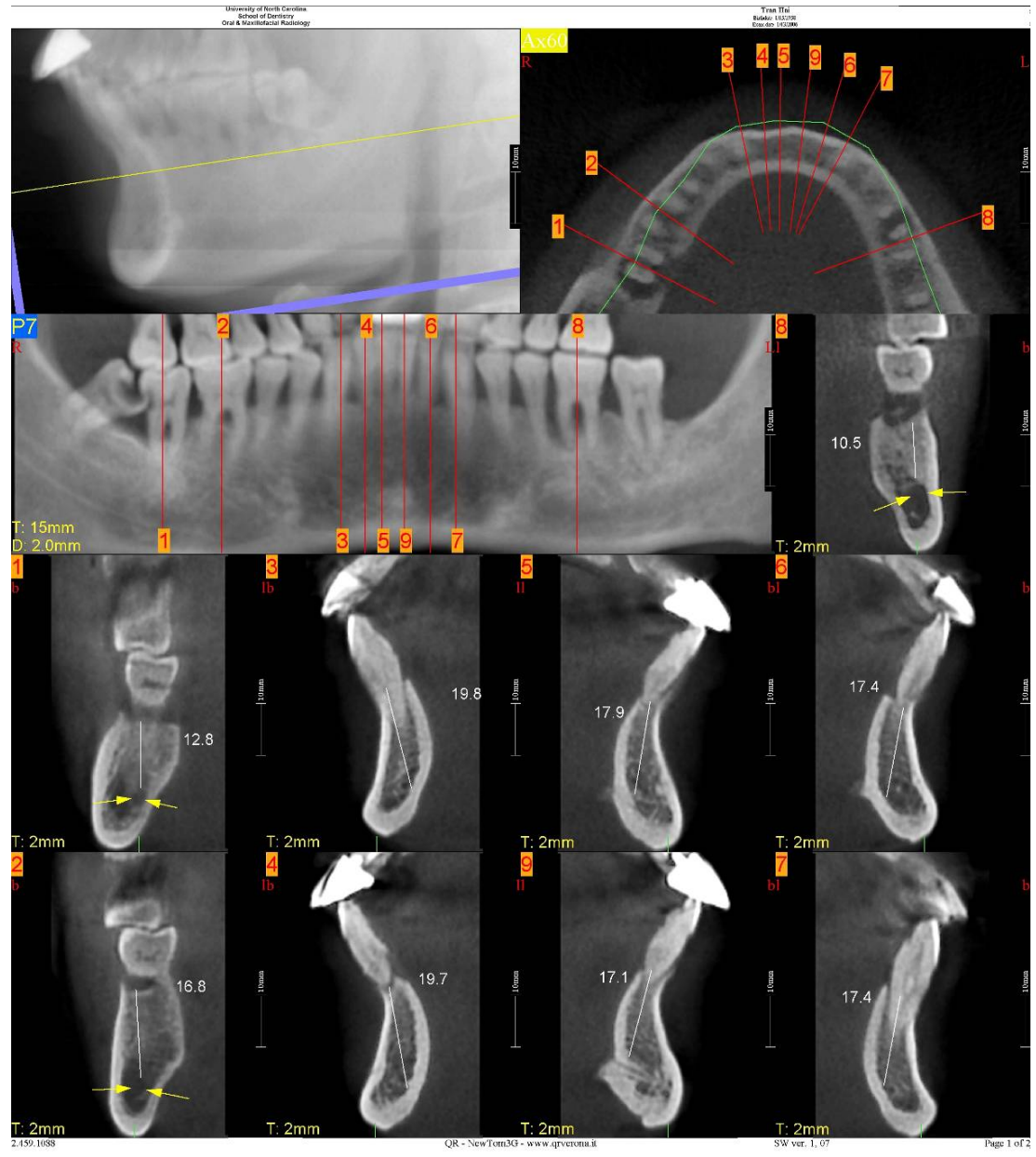


(Fig. 2). Contd...

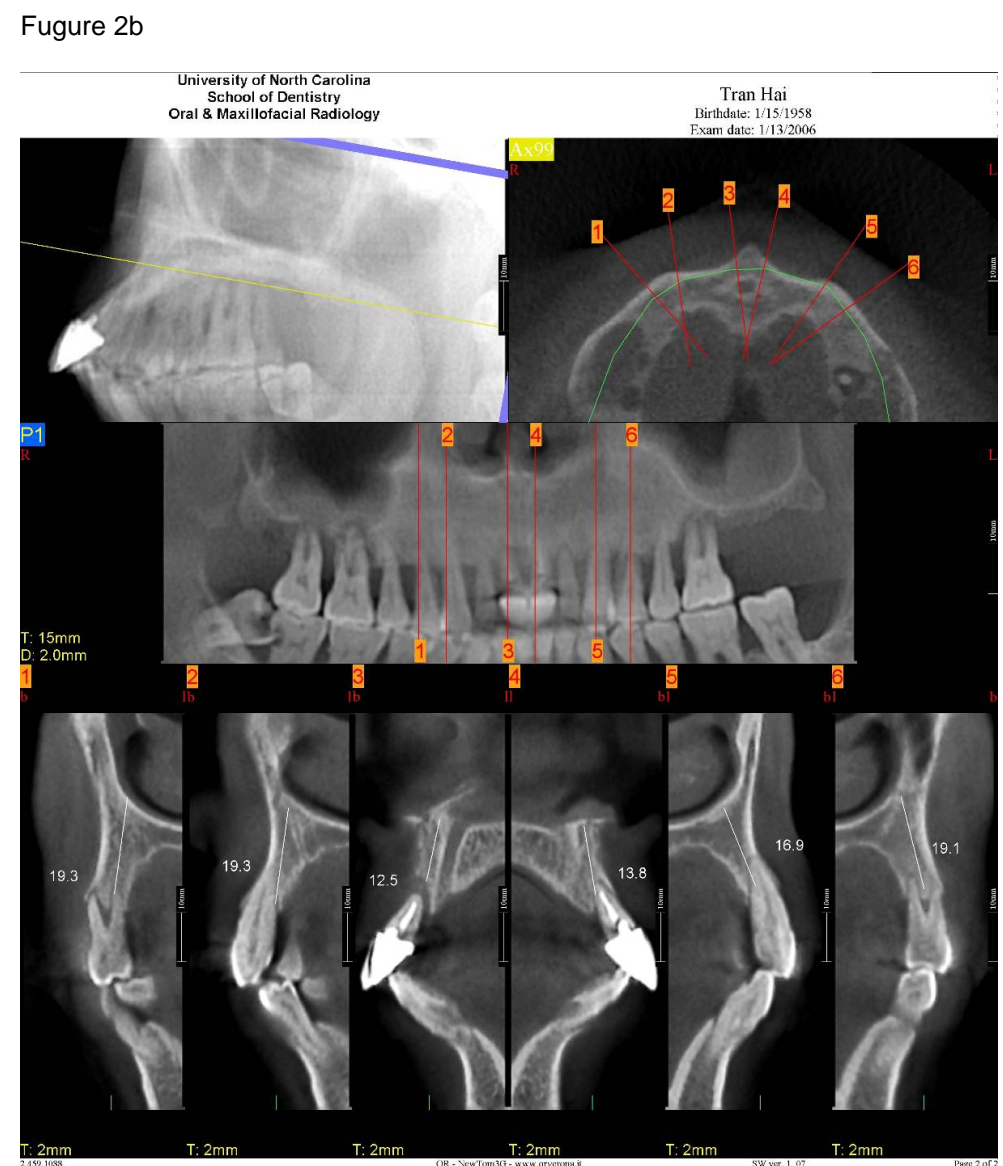

Fig. (2). a-b) Preoperative CT scans.

\section{Surgical Procedures and Interim Prostheses}

To minimize the number of surgeries and the length of healing time, we decided to perform two separate surgeries including (1) removal of his natural teeth; and (2) placement of dental implants. The patient was advised that heavy smoking can contribute to poor tissue healing and may reduce the success rate of implants [7-9]. As a result, he had stopped smoking the day before his first surgery.

In the first surgery, we removed all remaining natural teeth and delivered immediate dentures. Atraumatic extractions followed by socket hemostasis with gelatin sponge (Gelfoam, Pfizer) and sutures were performed. To reduce the occlusal force to the healing sockets, the immediate complete dentures were delivered with tissue conditioner (Coe Comfort, GC) (Fig. 3a-Immediate dentures).

Three weeks after the first surgery, we placed eleven Astratech ST implants (Astra Tech Inc, Waltham, MA, USA); five in the mandible ( $4.5 \times 15 \mathrm{~mm}$ for \#22, 23, 25, 27 and 4.5 $\mathrm{x} 9 \mathrm{~mm}$ for \#28) and six in the maxilla $(3.5 \times 11 \mathrm{~mm}$ for \#5, $3.5 \times 13 \mathrm{~mm}$ for \#13, $3.5 \times 15 \mathrm{~mm}$ for \# 8, 9 and $4.5 \times 15 \mathrm{~mm}$ for \#6,11). (Fig. 3b and c-Radiograph after extraction and implant placement). The second-stage surgery was performed ten weeks after the placement of dental implants. The implants were uncovered with a small crestal incision and the healing abutments were placed. After the implant placement and second-stage surgery, interim complete dentures were again relined with tissue conditioner (Coe Comfort, GC).

\section{Fabrication of Final Prostheses}

Three weeks after the second-stage surgery, we began the fabrication of final prostheses. Five $20^{\circ}$ Uniabutments (Astra Tech Inc, Waltham, MA, USA) were installed in the mandibular arch. Two $20^{\circ}$ Uni Abutments and four Angled Abutments (Astra Tech Inc, Waltham, MA, USA) were installed in the maxillary arch (Fig. 4a,b Abutments in placed). Final impressions (Fig. 4c,d Final impressions) were made using opened tray technique with impression transfer copings; Uni Abutment and Angled Abutment Pick-ups (Astra Tech Inc, Waltham, MA, USA) and ImprintII (3M ESPE). Centric relation and protrusive records were made with recording bases fabricated on the master casts.

Working casts were mounted together and cross-mounted with his interim dentures. Maxillary and mandibular metal frameworks were fabricated with paladium silver alloy (Aurolite 61-60.5\% Pd, 28\% Ag, and 2.5\% Sn; Argen Corp) using the guide from a putty matrix generated from the mounted casts of the interim dentures. We divided the maxillary restoration into two fixed partial dentures due to the size of castings. The frameworks were tested and new centric relation records were made with his interim maxillary dentures and between the maxillary and mandibular prosthetic frameworks (Fig. 5a,b,c Frameworks). 


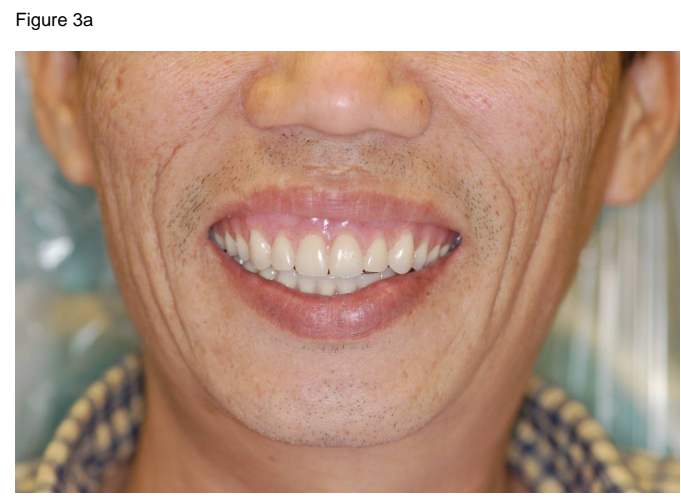

Figure $3 b$

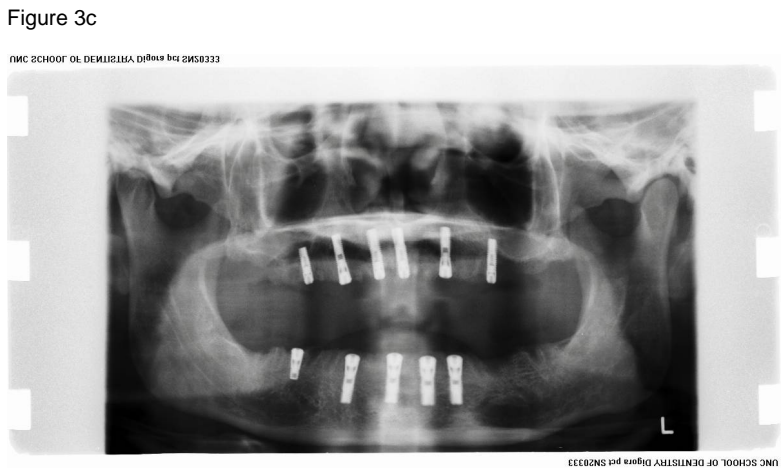

Fig. (3). a) Interim Prostheses.

b) Panoramic radiograph with interim prostheses in place showing the area planned for implant placement.

c) Panoramic radiograph after implant placement.

Figure $4 a$

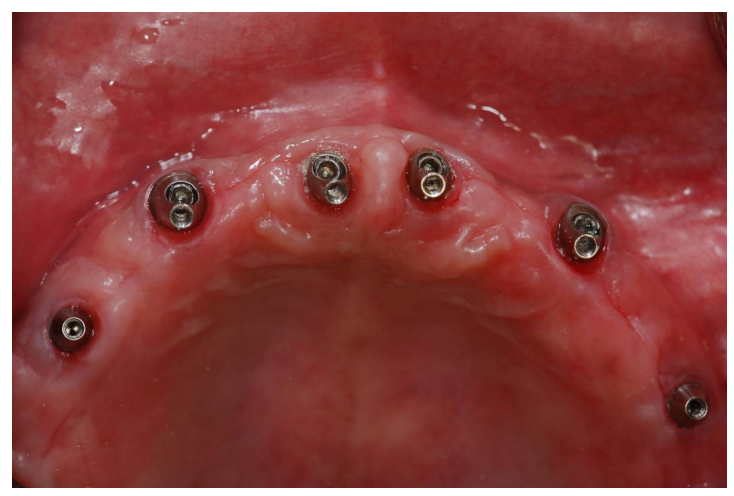

Figure 4c

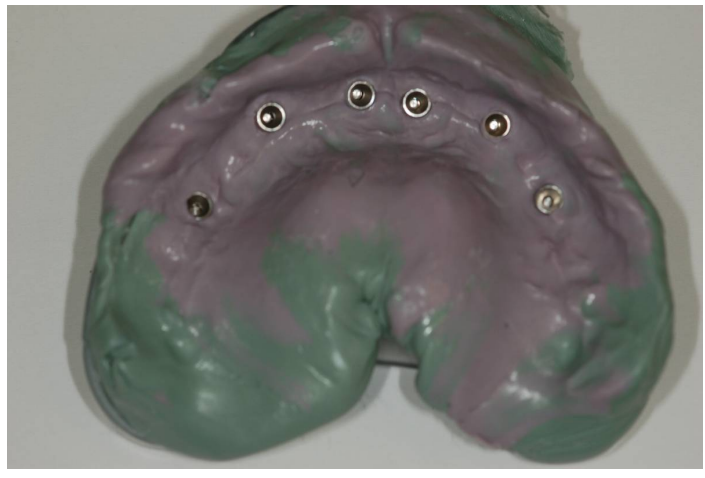

Figure $4 b$

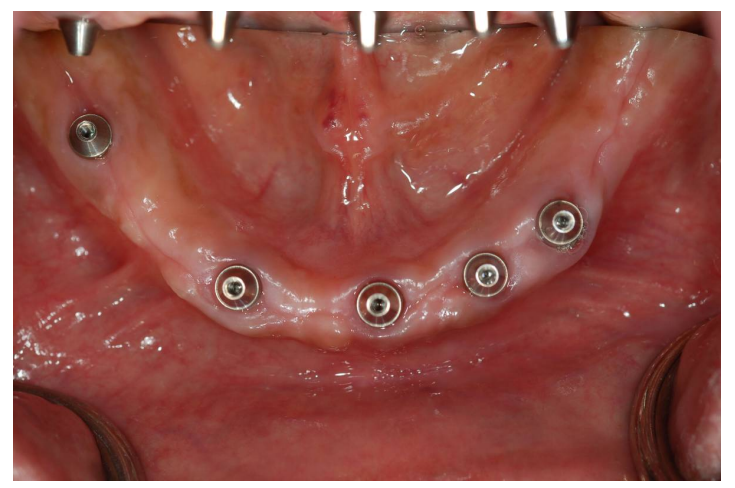

Figure 4d

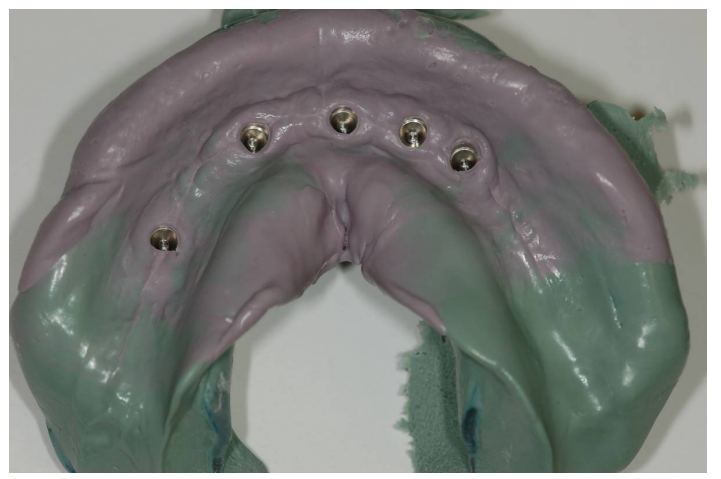

Fig. (4). a and b) Prefabricated abutments.

c and d) Final abutment-level impressions. 
Figure $5 a$

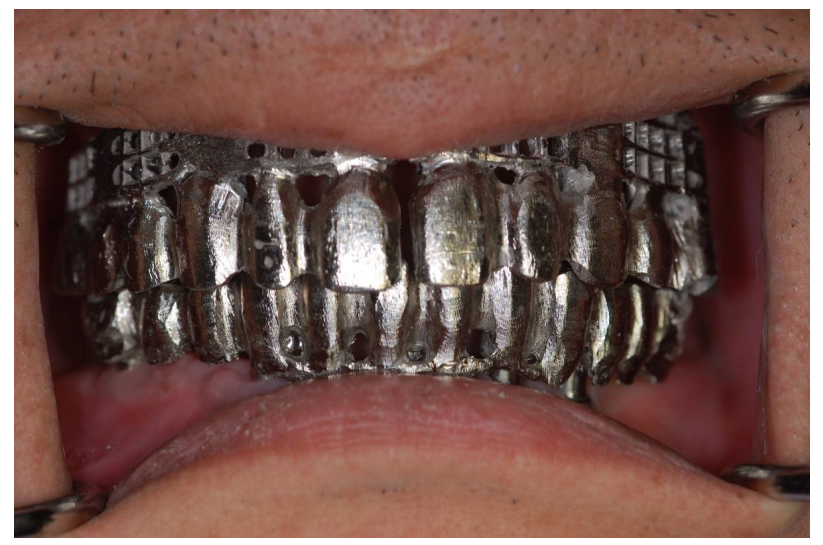

Figure 5b

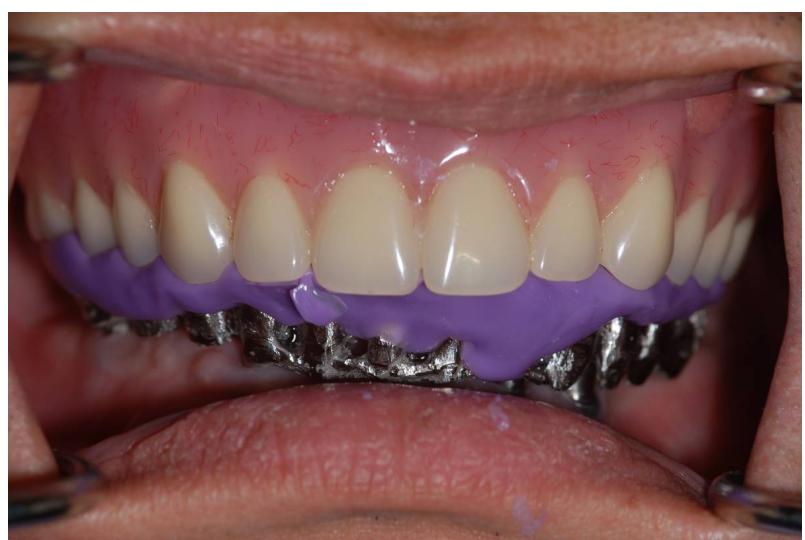

Figure 5c

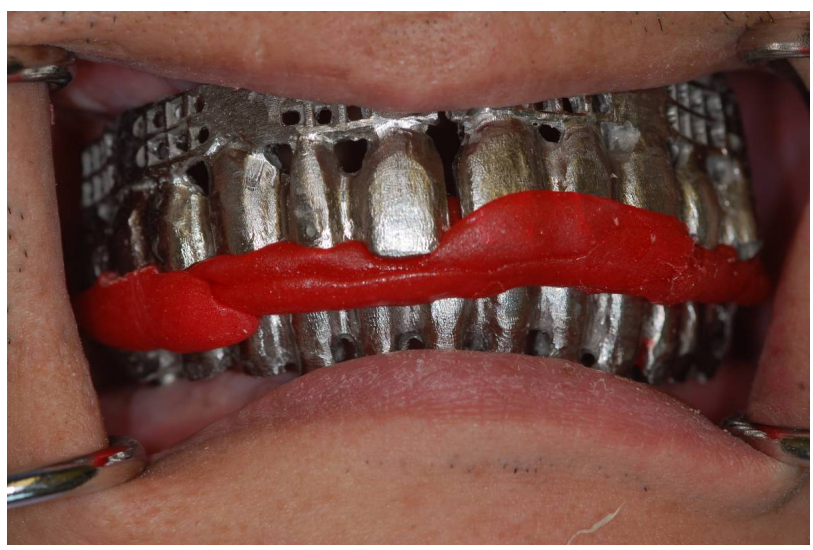

Fig. (5). a-c) Frameworks and inter-occlusal records.

The porcelain was fabricated with mutually protected occlusion. The prostheses were tested before the application of artificial gingival material. The occlusal contacts were evaluated and adjusted (Fig. 6a-porcelain tried in). The vertical dimension of occlusion was evaluated using existing interim dentures. We chose to use composite gingival material (GC Gradia Gum, GC America Inc, ILm USA) instead of pink porcelain, because of the severity of loss of periodontium. Pink porcelain would require more metal to support the porcelain which would contribute to the increased the weight of prostheses.

The final prostheses were delivered (Fig. $6 \mathbf{b}$ and $\mathbf{c}$-final prostheses, $\mathbf{d}$-Radiograph) with a maxillary occlusal splint. The prostheses screws were tighten to $25 \mathrm{~N} / \mathrm{cm}^{2}$. The screw access holes were filled with Fermit-N (Ivoclar Vivadent) and composite resin (Herculite XRV, Kerr). Oral hygiene instructions were also provided to the patient. The patient was instructed to wear the occlusal splint at night to prevent implant overloading from possible parafunction.

The patient was followed up one week, one month, three months, six months, one, two, and three years after the prostheses were delivered. The patients had a six-month-hygiene recall. There has been no clinical mobility. Panoramic radiographs were taken yearly (for three years since the implants were placed). A radiologist was consulted to examine if there is any peri-implant bone loss. Prior to treatment, the patient reported that he could not chew food properly, due to the mobility of his natural teeth. After delivery of the definitive prostheses, the patient reported that he was able to use anterior teeth with sandwiches, apples, and other food that he previously would not be able to use his natural teeth to bite or chew properly. The patient reported improvement of masticatory function and esthetics. He reported no difficulty in eating or speaking. No complications including fracture of prostheses, loosening of prostheses, abutments, or implants were found.

\section{DISCUSSION}

The biology of a healing tooth socket is a complex process. While immediate placement of an implant at the time of tooth extraction is widely accepted and studied, early placement of an implant in a few-week-old healing socket is not well-studied $[10,11]$. The three-week waiting period after full mouth extractions may contribute both locally at the extraction sites as well as systemically in the bone marrow and peripheral stem cells. Systemically, it was shown that broken limbs can increase circulating (peripheral) stem cells perhaps due to an activation of increased osteoblastic progenitor cells in bone marrow [12]. It was also demonstrated that increases in circulating osteoblastic stem cells peaked three weeks after the injury. However, currently it is not known if there will be an increase in osteoblastic stem cells in circulation after dental extractions. In addition, our patient had quit smoking after the extractions which may have also contributed to better tissue healing. How these local and sys- 
Figure 6a

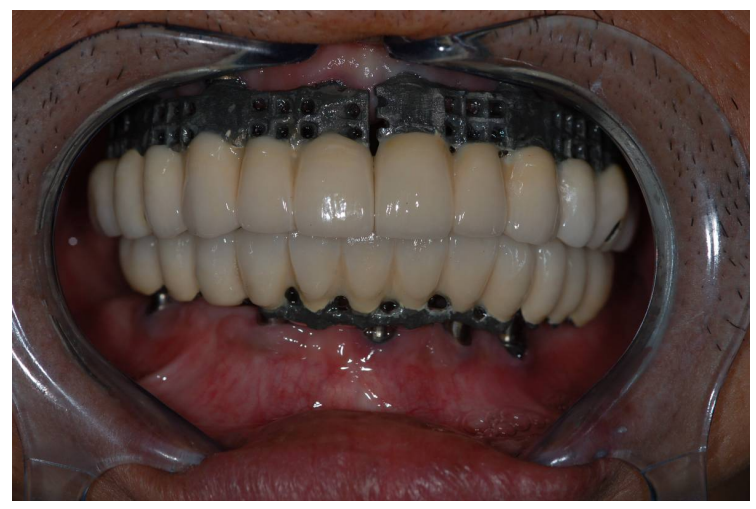

Figure 6c

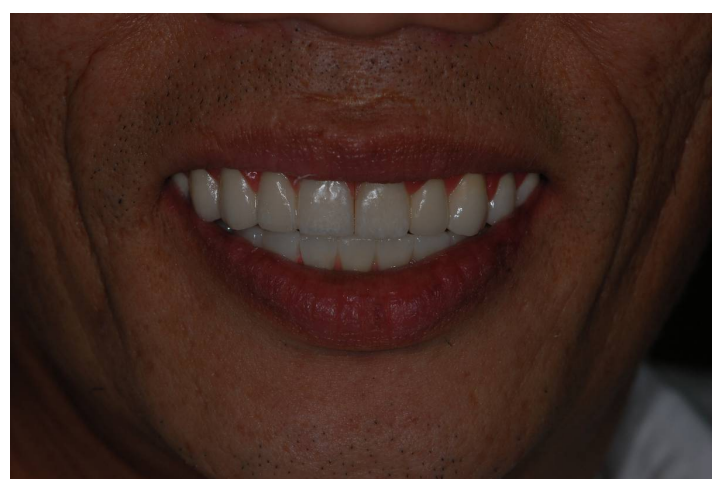

Figure $6 b$

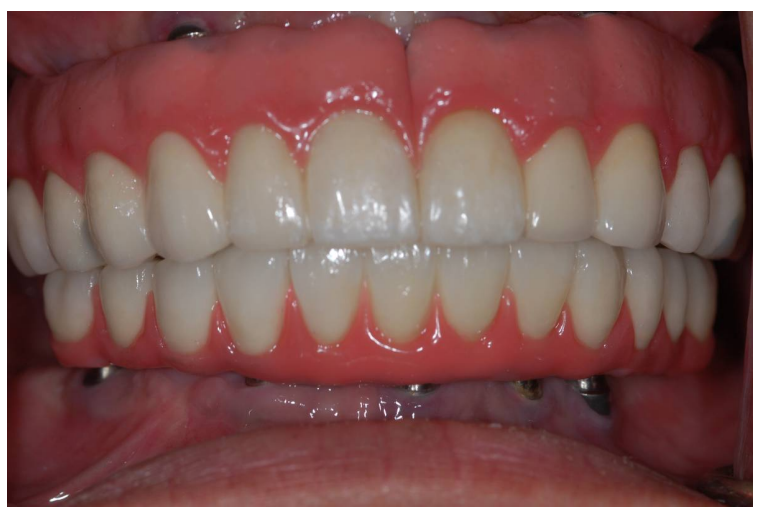

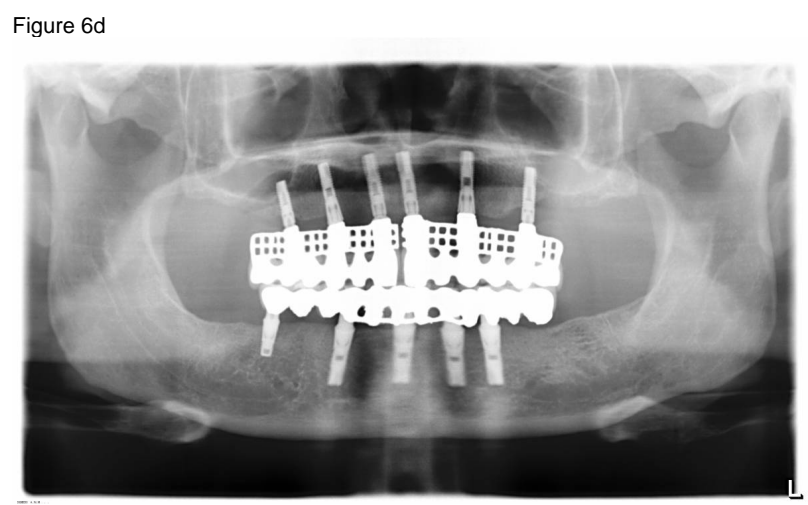

Fig. (6). a) Porcelain-fused to metal components.

b-d) Final prostheses.

temic factors contribute to the success of early placement implants are not known and will be a subject for future studies.

Early placement of implants within eight weeks after extractions seems to provide as high of a success rate as immediate placement and delayed placement (usually 2-3 months or more after extractions) of implants [13]. However, in terms of patient satisfactory, the early placement is significantly better than other techniques. Similar to immediate placement of dental implants after tooth extractions, we believe that primary stability of implants is necessary to ensure the success of implants. Primary stability of implants can be obtained by choosing appropriate implant width and length and utilizing remaining cortical bone $[14,15]$. While there are several studies looking into the early placement of implants, as we cited a systematic review [12, 13], there is, however, no specific report or recommendation of when is the optimal time to complete an early placement of dental implants after extractions. Several advantages occur when we separate the extraction visit and implant placement visit, including a reduction of surgical complexity, a minimization of operating time, and maximizing the fitting of the surgical stent. A three-week period of socket healing is also much shorter than 2-3 months.

Traditionally, pink porcelain is used for porcelain fused to metal restorations to replace missing periodontal or peri- implant tissues. However, the porcelain requires substantial support from the metal substructure. In our case, the metal substructure will be significantly heavier if pink porcelain was chosen. Recently, light-cured microfilled composite resin (GC Gardia Gum, GC America) has been introduced for esthetic artificial gingival tissue. According to the manufacturer, it is indicated for implant prostheses as well as conventional fixed and removable prostheses. We chose this material because of its esthetics, as well as to reduce the weight of the prosthesis since the composite material requires less metal substructure.

\section{CONCLUSION}

Severe loss of alveolar bone resulting from advanced periodontitis often presents a challenge in fabrication of a fixed prosthesis. The patient is often given the option of major bone grafting procedures which usually take several surgical visits and, therefore, delay the treatment time. We have learned two lessons from this case. First, the placement of implants three weeks after the tooth extractions can be an attractive alternative option that minimizes surgical visits and reduces waiting time for bone healing. Second, replacing missing gingival tissues with composite resin artificial gingival material may provide a better alternative to pink porcelain in cases of large implant-supported prostheses. 


\section{ACKNOWLEDGEMENTS}

Funding to support open access publication charges have been provided by the University of North Carolina at Chapel Hill (UNC) Vice Chancellor for Research Economic Development and the UNC campus libraries.

\section{REFERENCES}

[1] Heasman L, Stacey F, Preshaw PM, McCracken GI, Hepburn S, Heasman PA. The effect of smoking on periodontal treatment response: a review of clinical evidence. J Clin Periodontol 2006; 33: 241-53.

[2] Offenbacher S, Barros SP, Beck JD. Rethinking periodontal inflammation. J Periodontol 2008; 79(8 Suppl): 1577-84.

[3] Chiapasco M, Zaniboni M, Boisco M. Augmentation procedures for the rehabilitation of deficient edentulous ridges with oral implants. Clin Oral Implants Res 2006; 17(Suppl 2): 136-59.

[4] Aghaloo TL, Moy PK. Which hard tissue augmentation techniques are the most successful in furnishing bony support for implant placement? Int J Oral Maxillofac Implants 2007; 22(Suppl): 49-70.

[5] McAllister BS, Haghighat K. Bone augmentation techniques. J Periodontol 2007; 78: 377-96.

[6] Kfir E, Kfir V, Kaluski E. Immediate bone augmentation after infected tooth extraction using titanium membranes. J Oral Implantol 2007; 33: 133-8.

[7] Ong CT, Ivanovski S, Needleman IG, et al. Systematic review of implant outcomes in treated periodontitis subjects. J Clin Periodontol 2008; 35: 438-62.
Paquette DW, Brodala N, Williams RC. Risk factors for endosseous dental implant failure. Dent Clin North Am 2006; 50: 361-74

[9] Porter JA, von Fraunhofer JA. Success or failure of dental implants? a literature review with treatment considerations. Gen Dent 2005; 53: 423-32.

[10] Chen ST, Wilson TG Jr, Hämmerle CH. Immediate or early placement of implants following tooth extraction: review of biologic basis, clinical procedures, and outcomes. Int J Oral Maxillofac Implants 2004; 19(Suppl): 12-25.

[11] Schropp L, Isidor F.Timing of implant placement relative to tooth extraction. J Oral Rehabil 2008; 35(Suppl 1): 33-43.

[12] Eghbali-Fatourechi GZ, Lamsam J, Fraser D, Nagel D, Riggs BL, Khosla S. Circulating osteoblast-lineage cells in humans. N Engl J Med 2005; 352: 1959-66.

[13] Esposito MA, Koukoulopoulou A, Coulthard P, Worthington HV. Interventions for replacing missing teeth: dental implants in fresh extraction sockets (immediate, immediate-delayed and delayed implants). Cochrane Database Syst Rev 2006; 4: CD00596.

[14] Esposito M, Grusovin MG, Willings M, Coulthard P, Worthington HV. The effectiveness of immediate, early, and conventional loading of dental implants: a cochrane systematic review of randomized controlled clinical trials. Int J Oral Maxillofac Implants 2007; 22: 893-904.

[15] Greenstein G, Cavallaro J, Romanos G, Tarnow D. Clinical recommendations for avoiding and managing surgical complications associated with implant dentistry: a review. J Periodontol 2008; 79: 1317-29.

(C) Bencharit et al.; Licensee Bentham Open.

This is an open access article licensed under the terms of the Creative Commons Attribution Non-Commercial License (http://creativecommons.org/licenses/by-nc/3.0/) which permits unrestricted, non-commercial use, distribution and reproduction in any medium, provided the work is properly cited. 